\title{
Index of Languages
}

Abaza 20

Armenian

- Classical 172

- Western 138-139

Athpare 21

Baltic languages 7, 32, 44, 177, 223-224

Bambara 305-306

Bantawa 21

Bashkir 23

Beng 307

Bikol 254

Camling 21

Cebuano 254-255, 257

Chichewa 14

Coptic 7, 23-24

East Khanty 215, 231

English $5-7,22,65,97,100,112,136,138$, $160,170-173,183,248,267-268$, 296, 306

- Modern 36, 43, 139, 160

- Middle 24

- Old 41, 43, 64, 134, 139, 160

Erzya 215, 217-218, 222-223, 226-229

Estonian 215, 217, 219, 222-224

Finnic languages 7, 217, 219, 222, 224

Finnish 210, 213, 216, 223

Florentine, Old 277, 280, 283, 298

Fongbe 20

French 16, 22, 112, 159, 202, 265-268, 276 , 293-294, 295-298

- Classical 284, 287-288

- Contemporary 284, 287-288

- Middle 284, 286-288, 298

- Modern 284, 286-287, 290

- Old 16, 24, 265, 284, 286-288, 290, 298

- Pre-Classical 288

German 3, 6-7, 32, 34, 36, 47, 51, 139, 160 , 202, 267, 268
Germanic languages $31-32,34,36,41-42$, 44, 50-51, 59-60, 134, 139, 160, 171, 223-224

Gothic 7-8, 31-46, 49-51, 54-61, 63, 65-67, $69-71,134,139,160$

Greek 7, 14-15, 23-24, 31, 33-34, 42-44, $48,50,52-53,55,58-59,61,65-67$, 69-72, 139, 154, 157, 169-170, 173, 180, 182-183, 197, 201-203

- Ancient 48, 51-54, 145-146, 155, 175, 178-180, 182-183, 185, 188, 192-212

- Classical 9, 169, 175, 177-178, 188, 191-199, 201-204

- Hellenistic Koine 175, 193-194, 196, 198-201, 203

- Homeric 7, 9, 32, 53, 134, 139, 144, 169, 175-181, 184-185, 188, 191-193, 198, 201-204

- Katharévousa 183, 188, 195, 201

- Medieval 175, 186, 192-193, 195-200

- Modern 9, 139, 169-171, 173, 175. 181-183, 185-186, 188, 191, 193-205

- New Testament 48, 50, 53, 55, 57-59, 61, $65-66,69$

- post-Classical 192, 194

- post-Homeric 192

Haitian Creole 19-20

Hausa 138

Hittite $7,32,134,138-139,141,145,146$, 150-151, 155, 172

Hungarian 215, 218, 221-223, 226

Hup 20

Icelandic 32, 34, 51

- Old 41, 50, 65

Inari Saami 216, 219-222, 226, 228-229

Indo-Aryan languages 32, 153

Indo-European languages 7-9, 17-18, 31-32, $40,42,45-47,49,50,53,56-58,60$, 70-71, 89, 91, 133-134, 139, 160, 170, 178, 180-181, 194

Ingrian 219 
Irish, Old 6, 8, 89-102, 105, 107-109, 115, $121-123,125-127$

Italian 6, 10, 35-36, 59-60, 65, 92, 112, 158, 171-172, 265-268, 276-277, 282, 284, 293-295, 297-298

Jakarta Indonesian 171-172

Japhug 22-23

Kamas 215, 221

Kabardian 20

Karelian 219

Kartvelian 19

Kechwa (Lamas Kechwa) 21

Khoe 14

Kildin Saami 215, 227

Kiranti 21

Komi 215, 218, 221

Lai 138

Latin $6,8-10,32-33,43,53-55,64,90,98$, $101,111,113,123,126,133-135,137$, 140-143, 145-162, 180, 265-266, 269, 271-272, 290, 297-298

- Classical 8, 141, 147, 157, 161, 270-274, 297

- Early 151-152, 154, 271, 275

- Late 148, 151, 154, 273-278, 282, 295

- Vulgate 48, 59, 65-66

Laz 19

Livonian 215, 223-224

Madurese 255-257, 259

Manchu 21

Mapudungun 20

Mari 215, 218, 221, 223, 226, 228-229

Michif 22

Moksha 218, 227

Mordvinic languages 218, 227

Nadahup languages 20

Nakh-Daghestanian languages 7, 18

Nepali 21

Nganasan 215

Norse, Old 32, 41, 60
North Khanty 215, 217-218, 221, 223-226

North Mansi 212

North Saami 211-212, 216, 223, 226, 229

Old Church Slavonic 160

Pennsylvania German 20

Permic languages 231

Pisan, Old 280

Plains Cree 22

Portuguese 159

Proto-Germanic 32, 42, 47, 63, 64, 134, 139

Proto-Indo-European 7, 9, 32, 41, 47, 53, $60,63,64,71,133-134,170,177-179$, 181, 205

Proto-Uralic 217, 222, 226, 229

Puma 21

Quechua 21

Romance languages $8-9,133,135,147-148$, 152, 157-161, 171, 265-267, 269, 275-277, 282, 290, 298

Romani 19

Romanian 208

Russian 3, 18, 20, 22-23, 52, 138-139, 146, 219

Saamic languages 212, 214, 217, 221

Samoyedic languages 214, 226, 228

Sanskrit 134, 177

Selkup 215, 223, 226

Siberian Yupik 138

Sinitic languages 26

Slavic languages $7,19,44,166,171$

Soninke 8, 10, 305, 307-309, 311-317, 319-321, 323-326

South Saami 216, 221

Spanish 14, 20-21

Tagalog 238, 253-255, 257-259

Tatar 23

Tibetan 22-23

Totoli 8-10, 235-245, 247-252, 254-260

Tucanoan languages 20 
Tundra Nenets 215

Turkish 19, 184

Tuscan, Old 277

Udmurt 22-23, 202, 215, 218, 220-223

Ugric languages 224, 228

Uralic languages $7-9,18,22-23,209-230$
Veps $215,218-219$

Votic 215, 219

Waray-Waray 254

Western Austronesian languages 9-10, 235-237, 252-253, 260 
